USRF $_{\text {CSA }}$ was significantly reduced in stage I COPD patients compared to controls $\left(530 \mathrm{~mm}^{2}\right.$ vs $640 \mathrm{~mm}^{2} ; \mathrm{p}=0.0002$ ) (Abstract S94 figure 1); USRF $\mathrm{CSA}$ was also reduced in stages II $\left(526 \mathrm{~mm}^{2}\right)$, III $\left(503 \mathrm{~mm}^{2}\right)$ and IV $\left(509 \mathrm{~mm}^{2}\right)$ disease $(\mathrm{p}=0.0001)$. Daily physical activity was reduced in stage I patients (steps; $\mathrm{p}<0.0001$, PAL; $\mathrm{p}=0.002$ ) and stage II-IV COPD (steps and PAL; $\mathrm{p}<0.0001$ ) compared to healthy subjects. Using multivariate linear regression, $\mathrm{USRF}_{\mathrm{CSA}}(\mathrm{p}=0.0003)$, FFMI $(\mathrm{p}=0.0003)$ and the impedance ratio $(p=0.001)$ were all independent predictors of quadriceps strength in COPD. In stage I patients, only USRF $\mathrm{CSA}_{\mathrm{C}}$ was shown to be independently associated with daily physical activity (steps, $\mathrm{p}=0.03$; PAL, $\mathrm{p}=0.003$ ), while in stage II-IV disease, $\mathrm{FEV}_{1} \%$ predicted was retained as the only independent correlate with daily physical activity (steps and PAL, $\mathrm{p}<0.0001$ ).

Conclusions Quadriceps wasting identified by USRF CSA $_{\text {exists in }}$ patients with early, as well as advanced, COPD when compared to healthy age-matched controls. Quadriceps bulk is associated with daily physical activity independent of airflow obstruction, in early but not advanced disease. Our data suggest that, rather than being an end-stage phenomenon, quadriceps wasting is present in a substantial minority of COPD patients and is related to physical inactivity in the absence of severe airflow limitation.

\section{S95 EFFECT OF PULMONARY REHABILITATION ON CARDIOVASCULAR RISK FACTORS IN COPD}

doi:10.1136/thoraxjnl-2011-201054b.95

${ }^{1} \mathrm{~S} S \mathrm{C}$ Kon, ${ }^{2} \mathrm{~A} \mathrm{~L}$ Clark, ${ }^{2} \mathrm{~K}$ A Ingram, ${ }^{2} \mathrm{R}$ P Fowler, ${ }^{2} \mathrm{P}$ Marns, ${ }^{1} \mathrm{~J} \mathrm{~L}$ Canavan, ${ }^{1} \mathrm{M}$ S Patel, ${ }^{1} \mathrm{M}$ I Polkey, ${ }^{1}$ W D C Man. ${ }^{1}$ Respiratory Biomedical Research Unit, Royal Brompton \& Harefield NHS Foundation Trust, Harefield, Middlesex, UK; ${ }^{2}$ Harefield Pulmonary Rehabilitation Team, Harefield Hospital, Harefield, Middlesex, UK

Background Cardiovascular disease accounts for $27 \%$ of excess mortality seen in patients with chronic obstructive pulmonary disease (COPD). This may be attributed to the coexistence of cardiovascular risk factors such as smoking exposure and physical inactivity. Increased arterial stiffness has been demonstrated in patients with COPD, and this is an independent predictor of adverse cardiovascular events. Recent studies have shown that pulmonary rehabilitation (PR) can reduce blood pressure and arterial stiffness in COPD patients (Vivodtzev et al, 2009; Gale et al, 2011). However these studies comprised small numbers of highly selected patients. We investigated the effect of PR on resting blood pressure and heart rate in an unselected COPD population.

Methods 179 consecutive COPD patients completing an 8-week outpatient pulmonary rehabilitation programme were recruited. Resting blood pressure, heart rate, incremental shuttle walk (ISW) and Chronic Respiratory Disease Questionnaire (CRDQ) were measured immediately before and after PR. Paired t test (or nonparametric equivalent) was used to test the effect of PR

Results Following PR, there was no significant change in systolic, diastolic, mean arterial pressure and heart rate in all patients with

Abstract S95 Table 1 Effect of PR on haemodynamic variables in patients with COPD

\begin{tabular}{lccll}
\hline & $\begin{array}{l}\text { Before PR } \\
\text { mean }\end{array}$ & $\begin{array}{l}\text { After PR } \\
\text { mean }\end{array}$ & $\begin{array}{l}\text { Mean difference } \\
\text { (95\% Cl) }\end{array}$ & p Value \\
\hline Systolic BP (mm Hg) & 138.7 & 138.6 & $-0.0(-2.7$ to 2.6) & $\mathrm{ns}$ \\
Diastolic BP (mm Hg) & 86.2 & 86.0 & $-0.1(-10.8$ to 1.6) & $\mathrm{ns}$ \\
MAP (mm Hg) & 103.7 & 103.6 & $-0.1(-1.8$ to 1.6) & $\mathrm{ns}$ \\
Heart rate (bpm) & 81.8 & 80.8 & $-1.0(-2.7$ to 0.6$)$ & $\mathrm{ns}$ \\
ISWT (m) & 203.4 & 262.6 & $60.5(48.6$ to 72.5$)$ & $<0.0001$ \\
CRDO & 74.5 & 91.2 & $16.7(13.9$ to 19.5) & $<0.0001$ \\
\hline
\end{tabular}

COPD, although ISW and CRDQ improved significantly (see Abstract S95 table 1). Subset analysis in 124 COPD patients with no coexisting cardiovascular disease, diabetes or malignancy, and 31 patients with known hypertension also showed no significant change in blood pressure or heart rate.

Conclusions An 8-week outpatient PR programme has no effect upon resting heart rate or blood pressure in unselected patients with COPD.

\section{S96 SURVIVAL AFTER THE FIRST MYOCARDIAL INFARCTION IS SHORTER IN PATIENTS WITH COPD COMPARED TO THE GENERAL POPULATION}

doi:10.1136/thoraxjnl-2011-201054b.96

${ }^{1} \mathrm{~J} \mathrm{~K}$ Quint, ${ }^{1} \mathrm{E}$ Herrett, ${ }^{2} \mathrm{~A}$ Timmis, ${ }^{3} \mathrm{H}$ Hemingway, ${ }^{1} \mathrm{~L}$ Smeeth. ${ }^{1}$ London School of Hygiene \& Tropical Medicine, London, England; ${ }^{2}$ Barts \& The London NHS Trust, London, England; ${ }^{3}$ University College London, London, England

Background Patients with COPD are at increased risk of myocardial infarction (MI) compared to the general population and have shorter survival after any MI. We investigated whether this held true in patients with an "unanticipated" MI, defined as an MI occurring as the first manifestation of atherosclerotic disease and without any traditional cardiovascular risk factors and without any prior chest pain

Methods All patients experiencing their first MI between 1st January 2003 and 31st December 2008 as recorded in Myocardial Ischaemia National Audit Project (MINAP), who had no previous evidence of MI in their General Practice Research Database (GPRD) or MINAP record were included. Patients under 18 years of age, not registered with GPRD at the time of MI, or with $<1$ year of standard follow-up before their MI were excluded. Data were provided by the "Cardiovascular Disease Research Linking Bespoke Cohorts and Electronic Records" (CALIBER) group at UCL. The primary exposure of interest was diagnosis of COPD (defined in GPRD) and the outcome death after MI. Survival analysis was done using Kaplan-Meier methods. Cox proportional hazards models were used to adjust for potential confounders (age and sex).

Results 8065 individuals were included, 968 (12\%) of whom had a physician diagnosis of COPD made either before the first MI or during the follow-up period. 87 patients died on the day of admission $10(11.5 \%)$ of whom had COPD. The overall mortality rate was 160.2 deaths (95\%CI 145.5 to 176.5 ) per 1000 person years in those with COPD compared to 99.4 deaths (95.2 to 103.9) per 1000 person

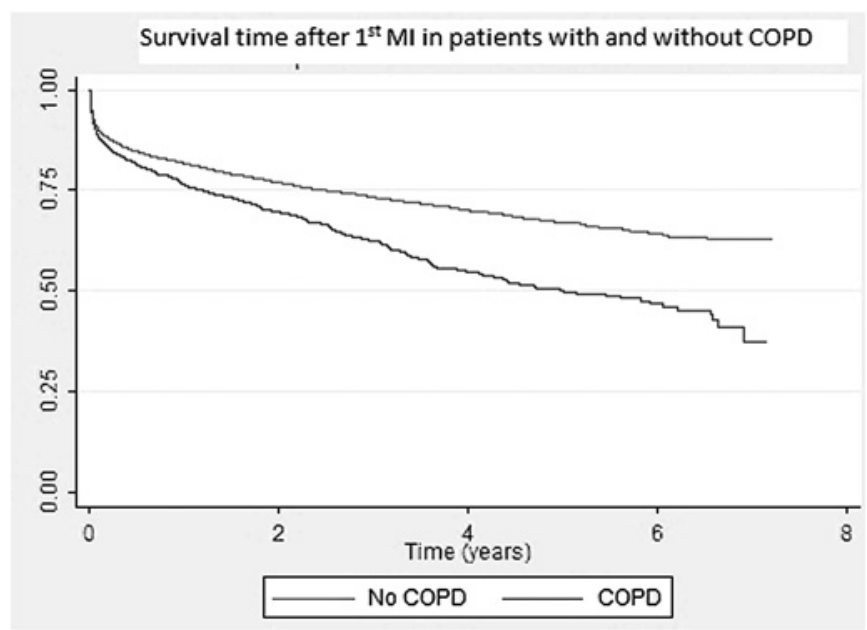

Abstract S96 Figure 1 Survival time after 1st MI patients with and without COPD. 